\title{
Resistance of villages to elevated-road traffic noise
}

\author{
Wen Luo Yu ${ }^{\mathrm{a}}$, Jian Kang ${ }^{\mathrm{a}, \mathrm{b}, *}$ \\ ${ }^{a}$ Heilongjiang Cold Region Architectural Science Key Laboratory, School of Architecture, Harbin Institute of \\ Technology, No.66, Xidazhi Street, Nangang District, Harbin, China; \\ ${ }^{b}$ School of Architecture, University of Sheffield, Western Bank, Sheffield S10 2TN, United Kingdom \\ * Corresponding author.
}

\begin{abstract}
The purpose of this study is to evaluate the methods of reducing elevated-road traffic-noise levels in rural residential areas by controlling the relative locations and morphological parameters and to investigate the effect of noise barriers on noise attenuation along elevated roads and building facades in villages. This study selected six morphological parameters and used noise-mapping techniques to estimate the noise attenuation in 60 village sites. The results indicate that 'quiet areas' increase by approximately $10 \%$ for each additional $100 \mathrm{~m}$ increase in the distance between the elevated road and the village. The best strategy for noise reduction is keeping the elevated road 1,000 $\mathrm{m}$ away from the village and raising the road height to $20 \mathrm{~m}$. The building façade conditions only affect the traffic noise level attenuation when the buildings are within $100 \mathrm{~m}$ of the elevated road. It was found that the cost-effective length of the road noise barrier is $600 \mathrm{~m}$ on both sides of the village parallel to the road. The results highlight the importance of using morphology to improve the traffic noise resistance of villages. The landscape shape indices of buildings and roads are the most important parameters that affect the traffic noise attenuation of elevated roads.
\end{abstract}

Keywords: Elevated road; Village; Morphology; Noise attenuation; Traffic noise

2018 Environmental Planning and Management

Date Received: 17 May 2017 Date Accepted: 11 Dec 2017

Published online: 15 Feb 2018.

\section{Introduction}

People's health and standard of living are significantly affected by the acoustic properties of their living environment (Sobotova et al., 2010; Fritschi et al. 2011). Thus, traffic noise is a public hazard that causes harm to the masses because of its large area of influence and long action time (Ko et al., 2011). With the acceleration of urban and rural integration processes in China, traffic systems between rural and urban areas have improved. Villages are rural residential areas where villagers live and engage in all types of production activities. Hence, it is important to address the serious problem of disturbance to villagers due to traffic noise (He and Kang, 2014; 
Meng and Kang, 2014; Murthy et al., 2010; Rey Gozalo, BarrigónMorillas, and Gómez Escobar, 2012; Rey et al., 2013; Xi, et al., 2015; Yari, et al., 2016).

To solve the problems related to traffic, ecology, geology, land resources, etc., elevated roads are preferred for inter-city traffic (Li and Yang, 2013; Liu, 2008; Wang and Kang, 2011; Wu, 1998). However, raising the sound source position will enlarge the noise diffusion area (Zhang, 2004), which inevitably aggravates the traffic noise pollution along these elevated roads (Chen et al., 2007; Yang, 2016; Ye , $\mathrm{Xia}$ and $\mathrm{Hu}, 2016$ ). To reduce traffic noise and increase the proportion of quiet areas, various solutions have been suggested: solutions based on road traffic volume, vehicle speed, and surface materials (Avsar and Gonullu, 2005; Li, Zhu, and Sun, 2007); those based on predictions of noise from elevated roads by using noise map techniques (Chen and Xiong, 2013; Li, Li and Li., 2012; Sun, Liu, and Wang, 2010; Zhang, 2014); controlling the propagation of traffic noise from elevated roads by using sound barriers (Ma and Li, 2009; Mei, Kang and Huang, 2016; Wang and Gai, 2012; Yu, 2008; Yu and Gao, 2013); using urban forms such as the influence of morphological parameters (Hao et al., 2015; Liu et al., 2014; Salomons and Pont, 2012); and improving the properties of buildings affected by the noise, e.g. through the design of architectural monomers (Kim and Kim, 2007; Wong et al., 2010; Yang Kang, and Choi, 2012).

Rural areas are significantly affected by the natural environment. Owing to the lack of professional guidance, the layout planning of buildings in rural areas is rather haphazard (Zhang and Yin, 2014). Because of high construction cost, buildings in rural areas are generally low-rise types, and their numbers have been growing rapidly (Shao, Jin, and Zhao, 2016; Wang, 2014). As previously mentioned (Chen et al., 2007; Chen and Xiong, 2013; Li , Li and Li., 2012; Ma and Li, 2009; Mei, Kang, and Huang, 2016; Sun, Liu and Wang, 2010; Wang and Gai, 2012; Yang, 2016; Ye, Xia and Hu, 2016; Yu, 2008; Yu and Gao, 2013; Zhang, 2004; Zhang, 2014), the numerous research results aimed at reducing noise along elevated roads in cities and towns are not entirely applicable to the village environment owing to economic constraints; however, there are even fewer studies on the subject of improving the resistance of villages to elevated-road traffic noise.

Therefore, this study aims to examine the influence of distance between villages and elevated roads, the height and sound barriers of elevated roads, and the materials of building facades in villages. It also aims to explore methods of integrating the effects of urban morphological parameters to improve the traffic noise resistance and create 
more quiet environments in rural residential areas in China (Hao and Kang, 2014; Lam et al., 2013; Wang and Kang, 2011). To analyse these parameters, a sequential noise mapping was performed for the selected typical villages.

\section{Methodology}

\subsection{Selection of sample village sites}

In this study, 60 villages in the Sanjiang and Songnen Plain in Heilongjiang (Fig. 1a) - the severely cold area and northernmost province of China - were selected because of their unique geographical location, variety of natural reserves, large peasant population, and the prominence of the plain area in Heilongjiang as a major grain-producing area according to the Heilongjiang Statistical Yearbook (2014). As shown in Fig. 1b, Heilongjiang has a transportation network comprising a motorway/elevated road and hierarchical traffic roads throughout the province. It has a plentiful river system: large rivers Heilong Jiang, Songhua Jiang, Wusuli Jiang, and Suifenhe. Moreover, many small-scale rivers have anastomosing reaches, where many viaducts are built, most of them for motorways that generate widespread traffic noise. Sixty research samples were chosen from Sanjiang Plain (Shuangyashan S1 to S14 and Kiamusze K1 to K16) and Songnen Plain (Harbin H1 to H30). Fig. 2 shows the serial numbers of the villages, range of the studied areas of the village, and the positional relationship between the villages and virtual (designed) elevated road ( $\mathrm{Yu}$ and Kang, 2016; Yu and Kang, 2017). The red lines representing the range of the studied areas of the village indicate the area enclosed by expanding the building zone of the villages and the outside edge line of the road by $20 \mathrm{~m}$.

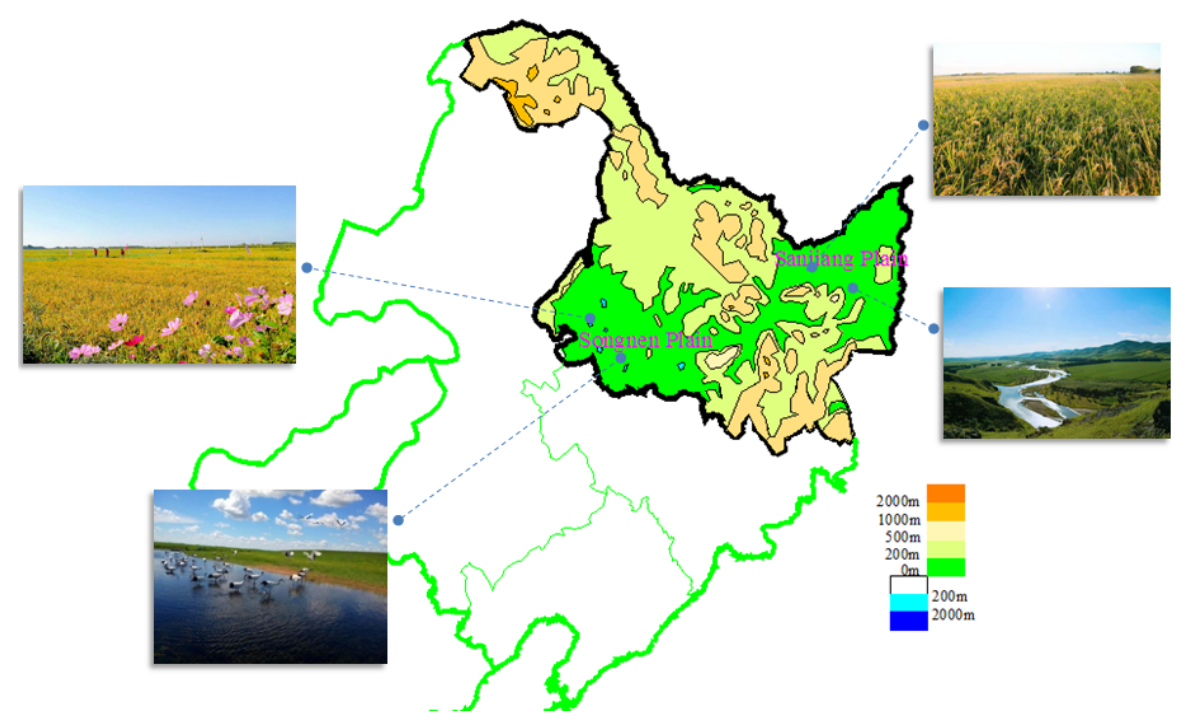

(a) 


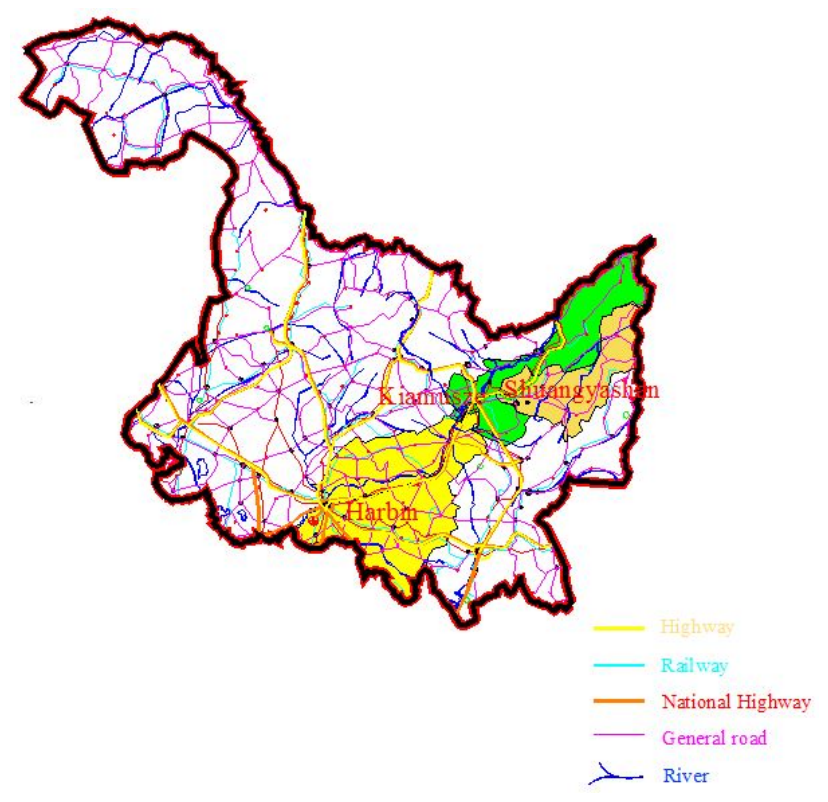

(b)

Figure 1. Locations of the study sites. (a) Contour map of Heilongiiang. (b) Roads and rivers in Heilongjiang.

\subsection{Selection of morphological parameters}

This study used previous research as a reference (Burian, Han, and Brown, 2005; Hao et al, 2015; Oke, 1988; Yu and Kang, 2016; Yu and Kang, 2017) and explored, developed, and used 12 morphological parameters to describe the characteristics of village forms in severely cold areas and comprehensively summarised the potential influencing factors of outdoor sound propagation such as geometric divergence, ground effects, canyon effect, and barrier effect (Kang, 2007). The building plan area fraction (BPAF), complete aspect ratio (CAR), landscape shape index of buildings (LSI_B), and patch density (PD) were mainly related to barrier attenuation, screening, and reflection. The landscape shape index of roads (LSI_R), road length fraction (RLF), distance of first-row building from the road (DFBR), and height-to-width ratio (HWR) were mainly related to geometric divergence, ground effects, and canyon effect. The edge density (ED), road intersections fraction (RIF), T-ratio (TR), and cell ratio (CR) were mainly associated with the village planning forms (Table 1) (Yu and Kang, 2016; Yu and Kang, 2017).

The morphological parameters of the villages failed to satisfy the mutually independent statistical properties (Table 2) ( $\mathrm{Yu}$ and Kang, 2016; Yu and Kang, 2017). Therefore, the method of factor analysis with equamax rotation was applied for screening and reducing the parameters. Four factors were identified which can explain approximately $88.14 \%$ of the variation in the 12 parameters (Table 3 ). In 


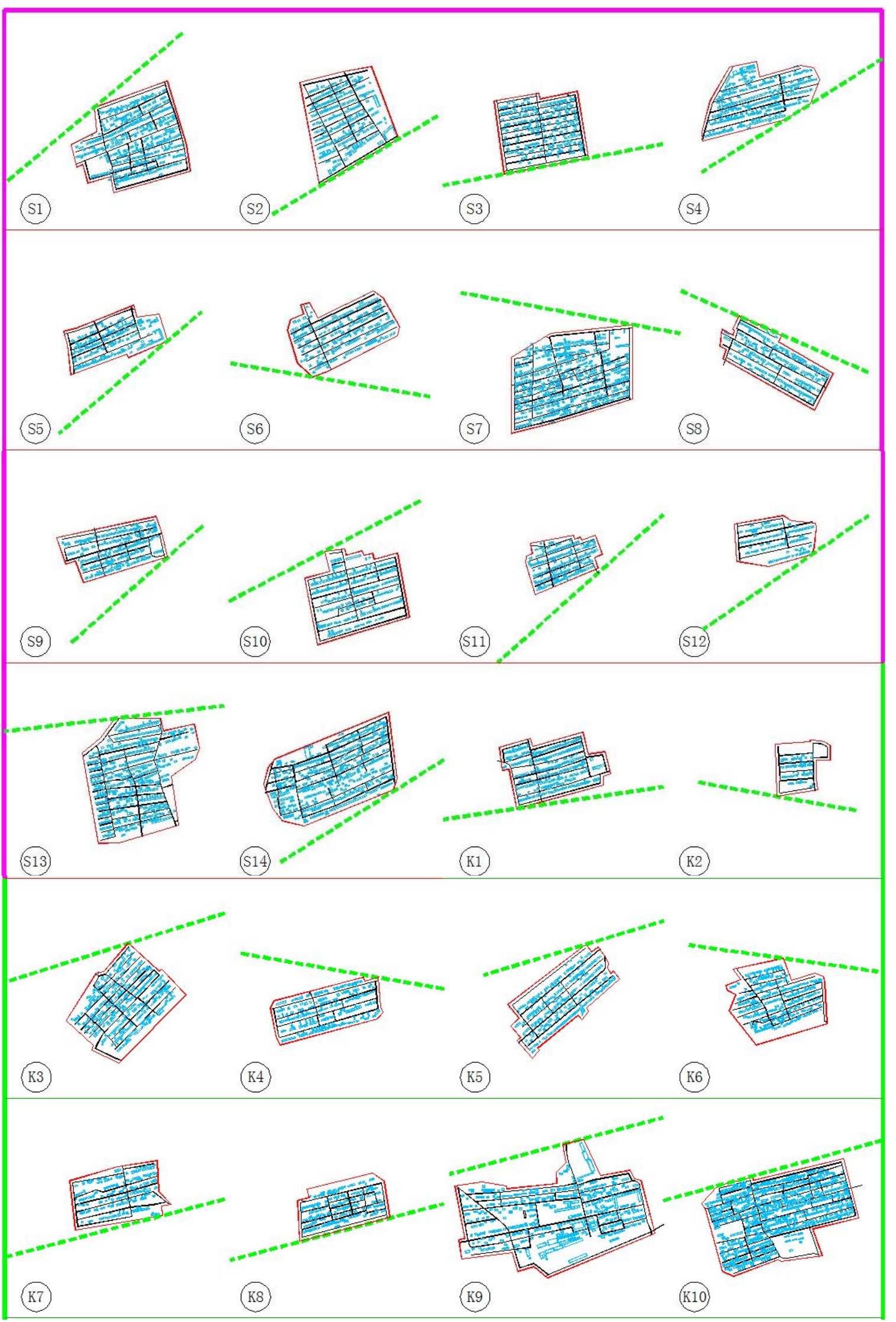


Wenluo Xu \& Sian Kang: Environmental Planning and Management

[DOI:10.1080/09640568.2018.1427560]

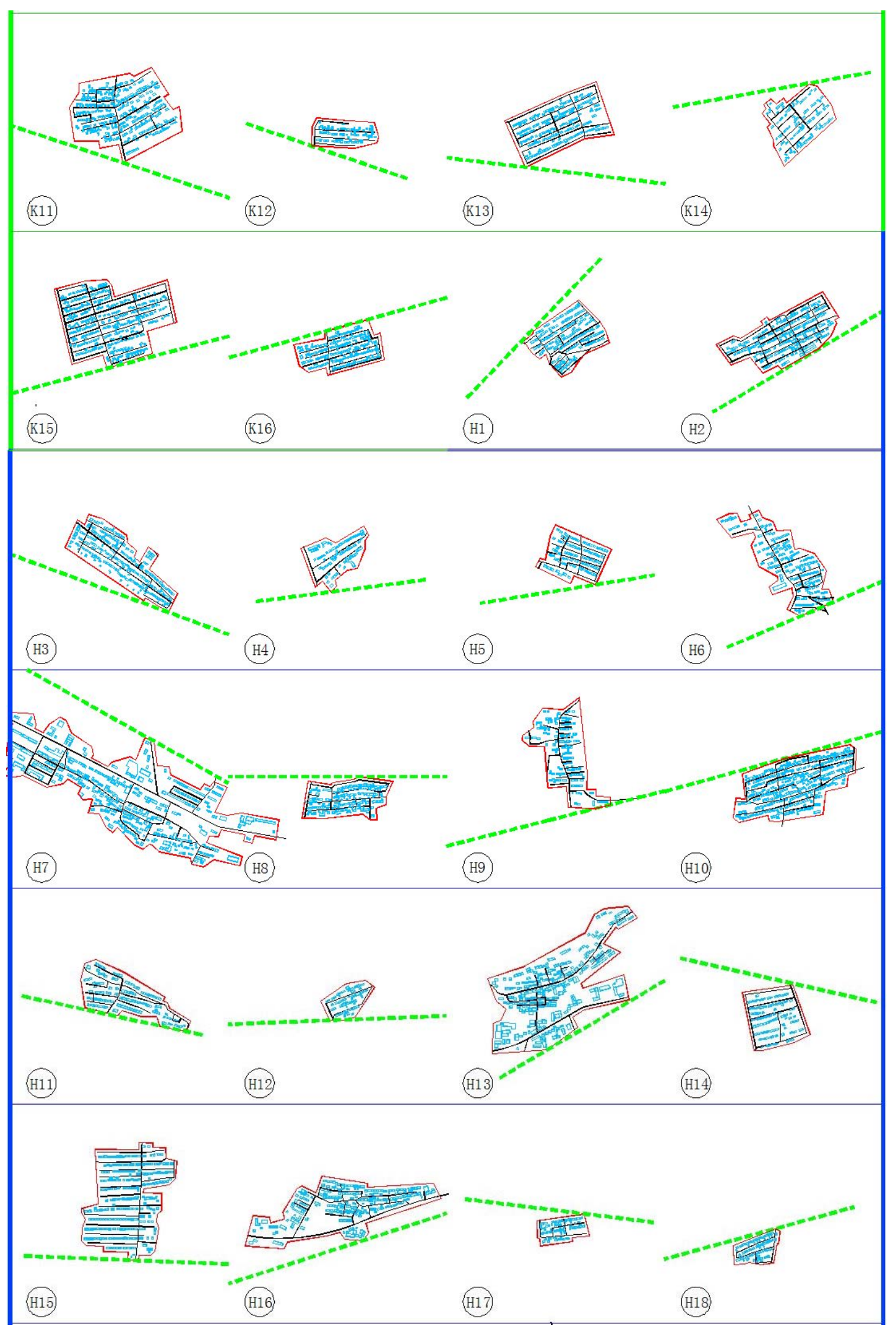

Environmental Planning and Management, Volume 61, Feb 2018, Pages 1-25

Page 6 


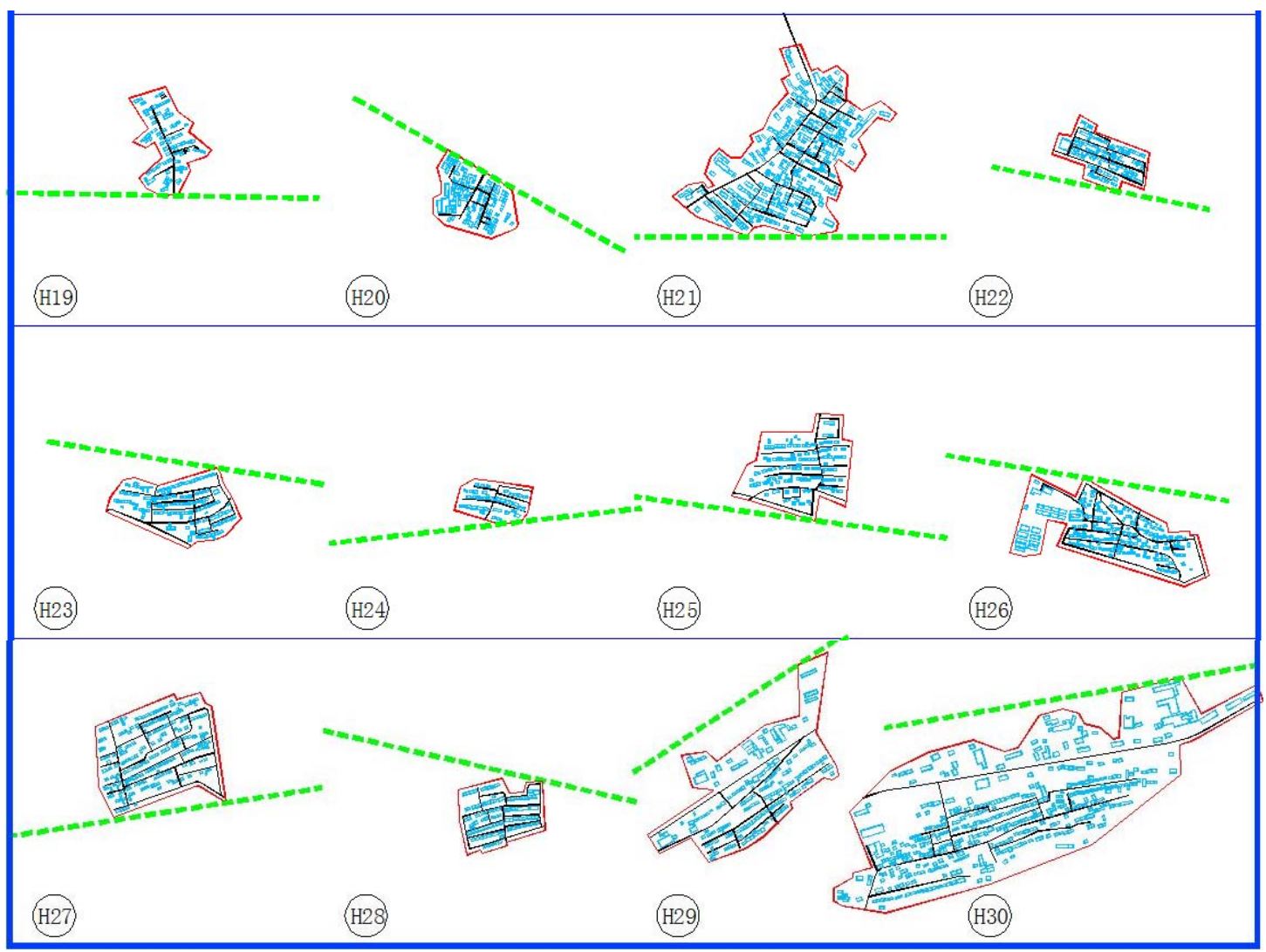

Figure 2. CAD image of the village sites based on Google Maps. Scale $=1: 1000$. S, K, and H are the abbreviation for city names where the village sites are located. The range of the studied areas of the village is shown in red lines; Elevated roads are coloured green, buildings are coloured blue, and roads are coloured black (Yu and Kang, 2016; Yu and Kang, 2017).

addition, an SRC analysis based on nonparametric estimation (He and Zhang, 2009) was used to examine the sensitivity of various parameters to the influence of subordinate common factors. Finally, the parameters that have higher absolute values of sensitivity coefficients are determined and retained from each factor, that is factor I: CAR and PD, factor II: LSI_B and LSI_R, factor III: RIF, and factor IV: RLF. The following six representative parameters that could objectively reflect the form of villages in severely cold areas were selected: CAR, LSI_B, PD, RLF, RIF, and LSI_R (Yu and Kang, 2016; Yu and Kang, 2017). 
Table 1. Formula for the calculation of the 12 urban morphological parameters (Yu and Kang,

2016; Yu and Kang, 2017).

\begin{tabular}{|c|c|c|c|c|}
\hline \multicolumn{5}{|c|}{ A: Mainly related to barrier attenuation, screening, and reflection } \\
\hline Parameter & Definition & Formula & Notes & Range \\
\hline BPAF & $\begin{array}{l}\text { The ratio of the plan area } \\
\text { of buildings to the total } \\
\text { surface area of the study } \\
\text { region }\end{array}$ & $\begin{array}{l}\text { BPAF } \\
=\mathrm{A}_{\mathrm{p}} / \mathrm{A}_{\mathrm{T}}\end{array}$ & $\begin{array}{l}\text { Ap is the plan area of buildings at ground level, } \\
\text { and } A_{T} \text { is the total plan area of the region of interest } \\
\text { (Burian et al., 2005). }\end{array}$ & $0.069-0.224$ \\
\hline CAR & $\begin{array}{l}\text { The summed area of } \\
\text { buildings and exposed } \\
\text { ground divided by the } \\
\text { total surface area of the } \\
\text { study region (Voogt and } \\
\text { Oke, 1997) }\end{array}$ & $\begin{array}{l}\mathrm{CAR}= \\
\frac{A_{w}+A_{r}+A_{\&}}{A_{T}}\end{array}$ & $\begin{array}{l}\text { Ac is the combined surface area of the buildings and } \\
\text { exposed ground, Aw is the wall surface area, Ar is the } \\
\text { roof area, and } A_{G} \text { is the area of the exposed ground } \\
\text { (Burian et al., 2005). CAR }>1 \text {. }\end{array}$ & $1.113-1.253$ \\
\hline LSI_B & $\begin{array}{l}\text { Landscape shape index of } \\
\text { buildings }\end{array}$ & $\begin{array}{l}\mathrm{LSI}= \\
\qquad \frac{0.25 E}{\sqrt{A}}\end{array}$ & $\begin{array}{l}\text { E is the total circumference boundary of buildings, } \\
\text { A is the total plan area of the region of buildings, and } \\
\text { LSI reflects the shape complexity of the whole landscape. }\end{array}$ & $5.824-24.103$ \\
\hline $\mathrm{PD}$ & Patch density & $\begin{array}{l}\mathrm{PD} \\
=10^{6} \mathrm{~N} / \mathrm{A}\end{array}$ & $\begin{array}{l}\text { Patch density has the same basic utility as the number of } \\
\text { patches as an index but facilitates comparisons among } \\
\text { landscapes of varying size. It is used as a measure of } \\
\text { landscape fragmentation. }\end{array}$ & $0.039-0.143$ \\
\hline
\end{tabular}

\section{B: Mainly related to geometric divergence, ground effects, and canyon effect}

\begin{tabular}{|c|c|c|c|c|}
\hline Parameter & Definition & Formula & Notes & Range \\
\hline LSI_R & $\begin{array}{l}\text { Landscape shape index of } \\
\text { village roads }\end{array}$ & $\mathrm{LSI}=\frac{0.25 E}{\sqrt{A}}$ & $\begin{array}{l}\text { E is the total circumference boundary of village roads, } \\
\text { A is the total plan area of the region of village roads. }\end{array}$ & $6.688-25.420$ \\
\hline RLF & Road length fraction & $\begin{array}{l}\mathrm{RLF} \\
=\mathrm{L}_{\mathrm{R}} / \mathrm{A}_{\mathrm{T}}\end{array}$ & $L_{R}$ is the length of the village roads at ground level. & $0.007-0.023$ \\
\hline DFBR & $\begin{array}{l}\text { The mean of the distances } \\
\text { from the front façades of } \\
\text { the first row of buildings } \\
\text { to the elevated road }\end{array}$ & $\begin{array}{l}\text { DFBR } \\
=\frac{1}{n} \sum_{i=1}^{n} d i\end{array}$ & $\begin{array}{l}n \text { is the total number of first-row buildings, and } d_{i} \text { is the } \\
\text { distance from the first-row buildings to the elevated road. }\end{array}$ & $9.604-42.393$ \\
\hline HWR & Height-to-width ratio & $\begin{array}{l}\text { HWR } \\
=\frac{H_{a v g}}{S_{a v g}}\end{array}$ & $\begin{array}{l}\mathrm{H}_{\text {avg }} \text { is the average of the building heights, } \\
\mathrm{S}_{\text {avg }} \text { is the average of the horizontal distances between } \\
\text { two adjacent buildings in the direction vertical to the } \\
\text { elevated road direction in the whole site region. }\end{array}$ & $0.053-0.162$ \\
\hline
\end{tabular}

\section{C: Mainly associated with the village planning forms}

\begin{tabular}{lllll}
\hline Parameter & \multicolumn{1}{c}{ Definition } & Formula & Notes & Range \\
\hline ED & The ratio of total length & ED & ED $\geq 0$, non-capped. & $0.193-0.391$ \\
& $\begin{array}{l}\text { of all patch boundaries } \\
\text { to the total patch area }\end{array}$ & & & \\
&
\end{tabular}




$\begin{array}{llll}\text { RIF } & \text { Road intersections } & \text { RIF } & \mathrm{N}_{\mathrm{I}} \text { is the total number of road intersections, }\end{array}$

Table 2. Spearman's rho correlations between urban morphological parameters (2-tailed). Significant correlations are marked with * $(\mathrm{p}<0.05)$ and ** $(\mathrm{p}<0.01)$ (Yu and Kang, 2016; Yu and Kang, 2017).

\begin{tabular}{|c|c|c|c|c|c|c|c|c|c|c|c|c|}
\hline & BPAF & CAR & LSI_B & $\mathrm{PD}$ & ED & RLF & $\mathrm{CR}$ & TR & RIF & LSI_R & DFBR & HWR \\
\hline BPAF & 1 & & & & & & & & & & & \\
\hline CAR & $.602 * *$ & 1 & & & & & & & & & & \\
\hline LSI_B & & & 1 & & & & & & & & & \\
\hline PD & $.323 *$ & $.840^{* *}$ & & 1 & & & & & & & & \\
\hline ED & $-.709 * *$ & & & $.299 *$ & 1 & & & & & & & \\
\hline RLF & & & & $.337 * *$ & $.323^{*}$ & 1 & & & & & & \\
\hline $\mathrm{CR}$ & & & & & & $.573 * *$ & 1 & & & & & \\
\hline TR & $.295^{*}$ & -0.066 & $-.326^{*}$ & & $-.371 * *$ & $-.276^{*}$ & & 1 & & & & \\
\hline RIF & & & & $.309^{*}$ & & $.804 * *$ & $.599 * *$ & & 1 & & & \\
\hline LSI_R & & & $.842 * *$ & & & $.297^{*}$ & $.337 * *$ & $-.403^{* *}$ & & 1 & & \\
\hline DFBR & & $-.297 *$ & & $-.388 * *$ & & & & & & & 1 & \\
\hline HWR & $.622 * *$ & $.768 * *$ & & $.601 * *$ & & & & & & $-.392 * *$ & $-.411 * *$ & 1 \\
\hline
\end{tabular}

Table 3. The results of the factorial analysis.

\begin{tabular}{lll}
\hline Factors & Parameters & $\begin{array}{c}\text { Explained } \\
(\boldsymbol{\%})\end{array}$ \\
\hline Factor I & CAR, BPAF, PD, ED, and DFBR & 33.91 \\
Factor II & LSI_B, LSI_R, and HWR & 28.46 \\
Factor III & RIF, CR, and TR & 15.75 \\
Factor IV & RLF & 10.02 \\
\hline
\end{tabular}

\subsection{Noise map}

To simulate the propagation and attenuation of traffic noise in villages in severely cold areas, noise maps were calculated with a commonly used noise-mapping package Cadna/A in this study [DataKustik, 2006]. The speed was taken into account according to the chosen standard, RLS 90. The measurement speed and 
speed limit were between $40 \mathrm{~km} / \mathrm{h}$ and $80 \mathrm{~km} / \mathrm{h}$ for trucks, and $60 \mathrm{~km} / \mathrm{h}$ and 100 $\mathrm{km} / \mathrm{h}$ for cars. The design speed was $80 \mathrm{~km} / \mathrm{h}$ for trucks and $100 \mathrm{~km} / \mathrm{h}$ for cars. The calculation was based on the calculation of road traffic noise model for roads, with values embedded in the software package, Cadna/A. The accuracy of the calculation was validated using the measurements obtained from villages in severely cold areas, although calculation errors were relatively higher at few measuring points, which were far away from the sound source. The average calculation error was less than 2 dBA (Mei, 2014; Meng, 2014). The sound absorption coefficient of the buildings was set as 0.2 , the number of times the propagated sound was reflected was set as 2 , the height of the receiving point was set as $1.5 \mathrm{~m}$, and the grid size of the analogy computation was set as $10 \mathrm{~m} \times 10 \mathrm{~m}$ (Meng and Kang, 2014; Yu and Kang, 2016; Yu and Kang, 2017).

Through field research, it was found that the majority of buildings in the villages in Heilongjiang Province are one-story buildings with pitched roofs (Shao, Jin and Zhao, 2016), indicating a typical, low-rise residential rural morphology. To reduce the time required for model construction and calculation, pitched roofs were simplified into flat roofs in the modelling. Therefore, it was necessary to increase the height of the eaves by $0.7 \mathrm{~m}$ and establish a model according to the building height of 4.5 m (Kang, 2007; Mei and Kang, 2014; Meng and Kang, 2014; Yu and Kang, 2016; Yu and Kang, 2017). Elevated roads comprise a series of bridges that are $6 \mathrm{~m}$ above the ground (net height including the structural height of the bridge). Table 4 shows the scenarios of the study in detail. When studying the reflection of sound from the building facades on the sound environment, this study compared and simulated the influence of two types of building facades. One type of building facade was composed of smooth hard materials (expressed as R3). The other type of building facade was composed of rough materials with a greening function or a good sound absorption effect (expressed as R0). The number of reflections for the simulation analysis of R3 and R0 was set as 3 and 0 , respectively, and the sound absorption coefficient of the building facades was set as 0.1 and 0.9 , respectively (Hao and Kang, 2014; Kang, 2007). The traffic volume per day of the motorway and rural road conform to the 'Design Specification for Highway Alignment' (JTG D20-2006). In this study, the traffic volume rates of the elevated road were set as 30,000 vehicles per day. If the traffic flow were doubled, the sound pressure level would increase by $3 \mathrm{dBA}$ (Avsar and Gonullu, 2005). Based on previous research results (Meng and Kang, 2014; Hao et al., 2015; Yu and Kang, 2016; Yu and Kang, 2017), this study divided the evaluation of sound pressure in outdoor spaces in the 
villages into three levels: $\mathrm{SPL}\left(\mathrm{L}_{\mathrm{Aeq}}\right) \leq 50 \mathrm{dBA}$ represented a quiet environment (quiet area), $50 \mathrm{dBA}<\mathrm{SPL}\left(\mathrm{L}_{\mathrm{Aeq}}\right) \leq 60 \mathrm{dBA}$ represented a normal sound environment with potential for improvement (less noisy area), and SPL ( $\left.\mathrm{L}_{\text {Aeq }}\right)>$ $60 \mathrm{dBA}$ represented a noisy environment (noisy area) in Table 4. Details of all scenarios in the study.

\begin{tabular}{|c|c|c|c|c|c|c|c|}
\hline \multirow{2}{*}{\multicolumn{2}{|c|}{$\begin{array}{c}\text { Scenarios } \\
\text { Elevated road data } \\
\text { based on virtual } \\
\text { (designed) road }\end{array}$}} & \multirow{2}{*}{$\begin{array}{c}3.1 \\
\text { Influence of } \\
\text { distance } \\
\text { between } \\
\text { elevated } \\
\text { road and } \\
\text { village on } \\
\text { sound } \\
\text { environment }\end{array}$} & \multicolumn{3}{|c|}{$\begin{array}{c}3.2 \\
\begin{array}{c}\text { Influence of height of elevated road on sound } \\
\text { environment of villages }\end{array}\end{array}$} & \multicolumn{2}{|c|}{$\begin{array}{c}3.3 \\
\begin{array}{c}\text { Influence of sound barrier of } \\
\text { elevated road }\end{array}\end{array}$} \\
\hline & & & $\begin{array}{c}3.2 .1 \\
\text { Influence } \\
\text { of height } \\
\text { of } \\
\text { elevated } \\
\text { road }\end{array}$ & \multicolumn{2}{|c|}{$\begin{array}{c}3.2 .2 \\
\text { Influence of sound barrier of } \\
\text { elevated road }\end{array}$} & $\begin{array}{c}3.3 .1 \\
\text { Relationship } \\
\text { between } \\
\text { sound } \\
\text { evaluation } \\
\text { indices and } \\
\text { morphological } \\
\text { parameters }\end{array}$ & $\begin{array}{c}3.3 .2 \\
\text { Relationship } \\
\text { between the } \\
\text { sound index } \\
\text { of traffic noise } \\
\text { and } \\
\text { morphological } \\
\text { parameters }\end{array}$ \\
\hline \multicolumn{2}{|c|}{$\begin{array}{c}\text { Horizontal } \\
\text { distances } \\
\text { between the site } \\
\text { and elevated } \\
\text { road } \\
\end{array}$} & $\begin{array}{l}0 \mathrm{~m}, 100 \mathrm{~m}, \\
300 \mathrm{~m}, 600 \mathrm{~m}, \\
\text { and } 1,000 \mathrm{~m}\end{array}$ & $0 \mathrm{~m}$ & \multicolumn{2}{|l|}{$0 \mathrm{~m}$} & \multicolumn{2}{|c|}{$0 \mathrm{~m}, 100 \mathrm{~m}$, and $300 \mathrm{~m}$} \\
\hline \multirow{2}{*}{\multicolumn{2}{|c|}{ Building facades }} & R2 & R2 & \multirow{2}{*}{\multicolumn{2}{|c|}{$\mathrm{R} 2$}} & \multirow{2}{*}{\multicolumn{2}{|c|}{ R2 }} \\
\hline & & $\mathrm{R} 3$ and $\mathrm{R} 0$ & & & & & \\
\hline \multicolumn{2}{|c|}{$\begin{array}{c}\text { Height of } \\
\text { elevated road }\end{array}$} & $10 \mathrm{~m}$ & $\begin{array}{l}10 \mathrm{~m}, 20 \\
\mathrm{~m}, \text { and } \\
30 \mathrm{~m}\end{array}$ & $10 \mathrm{~m}, 20 \mathrm{~m}$, and $30 \mathrm{~m}$ & $30 \mathrm{~m}$ & \multicolumn{2}{|c|}{$10 \mathrm{~m}$} \\
\hline \multirow[t]{2}{*}{$\begin{array}{l}\text { Sound } \\
\text { barrier }\end{array}$} & Height & \multirow{2}{*}{\multicolumn{2}{|c|}{$\begin{array}{l}\text { No sound barrier. } \\
\text { Set up a parapet for the } \\
\text { self-screening road on both } \\
\text { sides by entering a height } \\
\text { left/right }=1 \mathrm{~m} \text {. }\end{array}$}} & $3 \mathrm{~m}$ & $\begin{array}{l}2 \mathrm{~m}, 3 \mathrm{~m}, \\
4 \mathrm{~m}, \text { and } \\
5 \mathrm{~m}\end{array}$ & \multicolumn{2}{|c|}{$\begin{array}{c}3 \mathrm{~m} \text { sound barrier (village side) and } 1 \\
\mathrm{~m} \text { parapet (on the side away from the } \\
\text { village ) }\end{array}$} \\
\hline & Length & & & $\begin{array}{c}0 \mathrm{~m}, 200 \mathrm{~m}, 400 \mathrm{~m}, 600 \mathrm{~m}, \\
800 \mathrm{~m}, 1,000 \mathrm{~m}, 2,000 \mathrm{~m}, \\
3,000 \mathrm{~m}, \text { and 4,000 m }\end{array}$ & $4,000 \mathrm{~m}$ & \multicolumn{2}{|c|}{ more than $1,000 \mathrm{~m}$} \\
\hline
\end{tabular}

the subjective opinion of villagers in severely cold areas. In such an environment, villagers engaging in outdoor activities had an obvious aversion to traffic noise (Meng and Kang, 2014). However, in this study, quiet areas are defined in qualitative rather than in quantitative terms, which only presents a relative, rather than an absolute, definition of a quiet area; quiet areas are defined as areas having relatively low transport-related noise levels (during the daytime), even though $50 \mathrm{~dB}$ 
is still high as compared to the current noise evaluation criteria for night-time noise levels in the Class 2 standard (Environmental Quality Standard for Noise GB3096-2008). In addition, Lavg and Lmax were the average and maximum values, respectively, of the predicted sound pressure levels in the sample research areas. The statistical sound level Ln (L10-L90) refers to the value in the top $\mathrm{n} \%$ of the rankings of the spatial noise level values. Statistical sound levels, including L10, L50, and L90, are the acoustic parameters generally used to conduct studies and express the intrusive, median, and background sound levels respectively (Kang, 2007).

\section{Results}

\subsection{Influence of distance between elevated road and village on sound environment}

This study summarised the influence of the distance between five types of elevated roads and a village on the acoustic variable data of 60 sample villages, i.e. $0 \mathrm{~m}, 100$ $\mathrm{m}, 300 \mathrm{~m}, 600 \mathrm{~m}$, and $1,000 \mathrm{~m}$ (based on the principles of inverse square law of sound, the greater the distance, the larger the distance interval) in which $100 \mathrm{~m}$ is in line with the rules of Beijing Environmental Protection Agency: Within $100 \mathrm{~m}$ from the red line of the Third Ring Road, it is not allowed to create noise-sensitive buildings along the road (Zhang and Rao, 2012). This study found that the noise reduction effects of the various sample villages were evident and showed great differences with the increase in distance. To show that the noise reduction effects of the various sample villages have great differences with the increase in distance by a sensitive index, L10 was selected as it is more sensitive, with a higher variance, compared to L20-L90. This study considered an elevated road with a height of $10 \mathrm{~m}$ as an example. When the distance increased from $0 \mathrm{~m}$ to $100 \mathrm{~m}, 300 \mathrm{~m}, 600 \mathrm{~m}$, and $1,000 \mathrm{~m}$, the smallest decrease in L10 was observed for village $\mathrm{K} 9$, from among the 60 villages, for which L10 decreased by $2.1 \mathrm{dBA}, 5.3 \mathrm{dBA}, 8.9 \mathrm{dBA}$, and $12.9 \mathrm{dBA}$, respectively. For the various aforementioned distances, the village that exhibited the greatest noise reduction varied. When the distance increased from $0 \mathrm{~m}$ to $100 \mathrm{~m}$, $\mathrm{K} 10$ showed the greatest reduction in noise of $4.2 \mathrm{dBA}$. When the distance increased from $0 \mathrm{~m}$ to $300 \mathrm{~m}$ and $600 \mathrm{~m}, \mathrm{H} 1$ showed the greatest noise reduction of $8.9 \mathrm{dBA}$ and $13.1 \mathrm{dBA}$, respectively. When the distance increased from $0 \mathrm{~m}$ to $1,000 \mathrm{~m}, \mathrm{H} 20$ showed the greatest noise reduction of $17.9 \mathrm{dBA}$. The difference in the reduction of L10 among the villages reached a maximum of $5 \mathrm{dBA}$ with the increase in distance.

On comparing the results obtained using the inverse square law of sound, i.e. the sound field situation of the line sound source at a height of $10 \mathrm{~m}$ in an open space, it 
could be observed that the average noise reduction amplitudes in the open space were $4.7 \mathrm{dBA}, 12.6 \mathrm{dBA}, 18.9 \mathrm{dBA}$, and $24.9 \mathrm{dBA}$, which were greater than the sound attenuation amplitudes at the various villages with maximum noise reduction when the distance increased from $0 \mathrm{~m}$ to $100 \mathrm{~m}, 300 \mathrm{~m}, 600 \mathrm{~m}$, and $1,000 \mathrm{~m}$, as shown in Table 5. Thus, by comparing the two scenarios (village and open space), it is shown that villages were less affected by the distance between the elevated road and the village than the effects of the inverse square law of sound propagation on open space. According to this comparison and the simulation, the effect of the reflection of sound from the ground decreased while that from the buildings became significant. Therefore, it was necessary to consider the design of the building facades and urban morphological parameters in sites.

Table 5. Noise decreases in the two scenarios (village and open space).

\begin{tabular}{|c|c|c|c|c|}
\hline \multirow[t]{2}{*}{$\begin{array}{c}\text { Distance increased } \\
(\mathbf{m})\end{array}$} & \multicolumn{3}{|c|}{$\begin{array}{l}\text { Noise decreases in } 60 \text { village sites } \\
\text { (dBA) }\end{array}$} & \multirow{2}{*}{$\begin{array}{c}\begin{array}{c}\text { Noise decrease in the open } \\
\text { space (dBA) }\end{array} \\
\text { Average }\end{array}$} \\
\hline & Min & Average & Max & \\
\hline $0 \mathrm{~m}$ to $100 \mathrm{~m}$ & $2.1(\mathrm{~K} 9)$ & 3.2 & $4.2(\mathrm{~K} 10)$ & 4.7 \\
\hline $0 \mathrm{~m}$ to $300 \mathrm{~m}$ & 5.3 (K9) & 7.4 & $8.9(\mathrm{H} 1)$ & 12.6 \\
\hline $0 \mathrm{~m}$ to $600 \mathrm{~m}$ & 8.9 (K9) & 11.5 & $13.1(\mathrm{H} 1)$ & 18.9 \\
\hline $0 \mathrm{~m}$ to $1,000 \mathrm{~m}$ & 12.9 (K9) & 15.9 & $17.9(\mathrm{H} 20)$ & 24.9 \\
\hline
\end{tabular}

In the case of some samples of a typical village form, the proportion of quiet areas could increase by approximately $10 \%$ for each increase of $100 \mathrm{~m}$ in distance. When the distance was equal to or greater than $300 \mathrm{~m}$, N60 was 0 and there was no "noisy area' in the villages. When the distance was greater than 1,000 m, Lmax $<50 \mathrm{dBA}$, and all the sample villages became 'quiet areas' (Table 6). In accordance with '7.2 Determination of Sound Environmental Functions in Rural Areas' of China's Environmental Quality Standard for Noise (GB3096-2008), the requirements of the quality of sound environment 'LAeq' are generally as follows: convalescence and rehabilitation areas in villages follow the provisions of Class 0 sound environment functional areas (these refer to areas that specifically require quietness and at which the environmental noise LAeq should be maintained at a value less $50 \mathrm{dBA}$ in the daytime); villages that follow the requirements of Class 1 sound environment functional areas in principle (these refer to areas that require low noise, such as buildings, medical health, and cultural sports, as the main functions, and the environmental noise $\mathrm{L}_{\text {Aeq }}$ is limited to within $55 \mathrm{dBA}$ in the daytime); villages that engage in numerous industrial activities and have traffic arteries passing through them can partly or completely follow the requirements of Class 2 sound environment 
Table 6. Variances of the mean traffic noise level, noise area categories (\%), and spatial noise level indices $\operatorname{Ln}(\mathrm{dBA})$ among the 60 sites with horizontal distances between the site and elevated roads of $0 \mathrm{~m}, 100 \mathrm{~m}, 300 \mathrm{~m}, 600 \mathrm{~m}$, and 1,000 m.

\begin{tabular}{ccccccccc}
\hline Distance (m) & \multicolumn{3}{c}{ Noise area categories (\%) } & \multicolumn{3}{c}{ Spatial noise level indices, dBA } \\
& Quiet area & Less Noisy Area & Noisy Area & Lmax & L10 & L50 & L90 \\
\hline $\mathbf{0}$ & 9.84 & 68.60 & 21.56 & 64.40 & 61.43 & 55.64 & 51.35 \\
$\mathbf{1 0 0}$ & 18.28 & 77.04 & 4.68 & 61.63 & 58.19 & 53.21 & 49.30 \\
$\mathbf{3 0 0}$ & 48.44 & 51.56 & 0.00 & 56.32 & 54.03 & 50.05 & 46.26 \\
$\mathbf{6 0 0}$ & 89.75 & 10.25 & 0.00 & 51.72 & 49.94 & 46.53 & 42.74 \\
$\mathbf{1 , 0 0 0}$ & 100.00 & 0.00 & 0.00 & 47.02 & 45.58 & 42.69 & 38.93 \\
\hline
\end{tabular}

functional areas (these refer to areas that require maintenance of residential quietness, that include country fair trade as the main function or single dwelling, commerce, and industry, and in which the environmental noise LAeq is limited to within $60 \mathrm{dBA}$ in the daytime). Therefore, in these cases, the standard of Class 2 sound environment functional areas would be satisfied when the distance between an elevated road and a site is $300 \mathrm{~m}$; that of Class 1 environment would be satisfied when the distance between an elevated road and a site is $600 \mathrm{~m}$, and Class 0 standard would be satisfied when the distance between an elevated road and a site is more than 1,000 m.

For a distance of less than $300 \mathrm{~m}$, this study compared and studied two types of building facades, namely R3 (very smooth) and R0 (very rough or covered with greenery). When the distance between the village and elevated road (10 $\mathrm{m}$ high) is $0 \mathrm{~m}$, changing the building facades from R3 to R0 could cause a decrease in N60 of the 60 samples by an average of $11.27 \%$. When the distance is $100 \mathrm{~m}$, N60 could decrease by $3.17 \%$ on average. When the distance is greater than $100 \mathrm{~m}$, the influence is negligible. Therefore, the effective distance seems to be approximately $100 \mathrm{~m}$ (Fig. 3) for the noise reduction design of building facades. In terms of Q50, when the distance is $0 \mathrm{~m}, 100 \mathrm{~m}$, and greater than $100 \mathrm{~m}$, Q50 could only increase by $0.52 \%, 0.27 \%$, and 0 , which have negligible influence. 


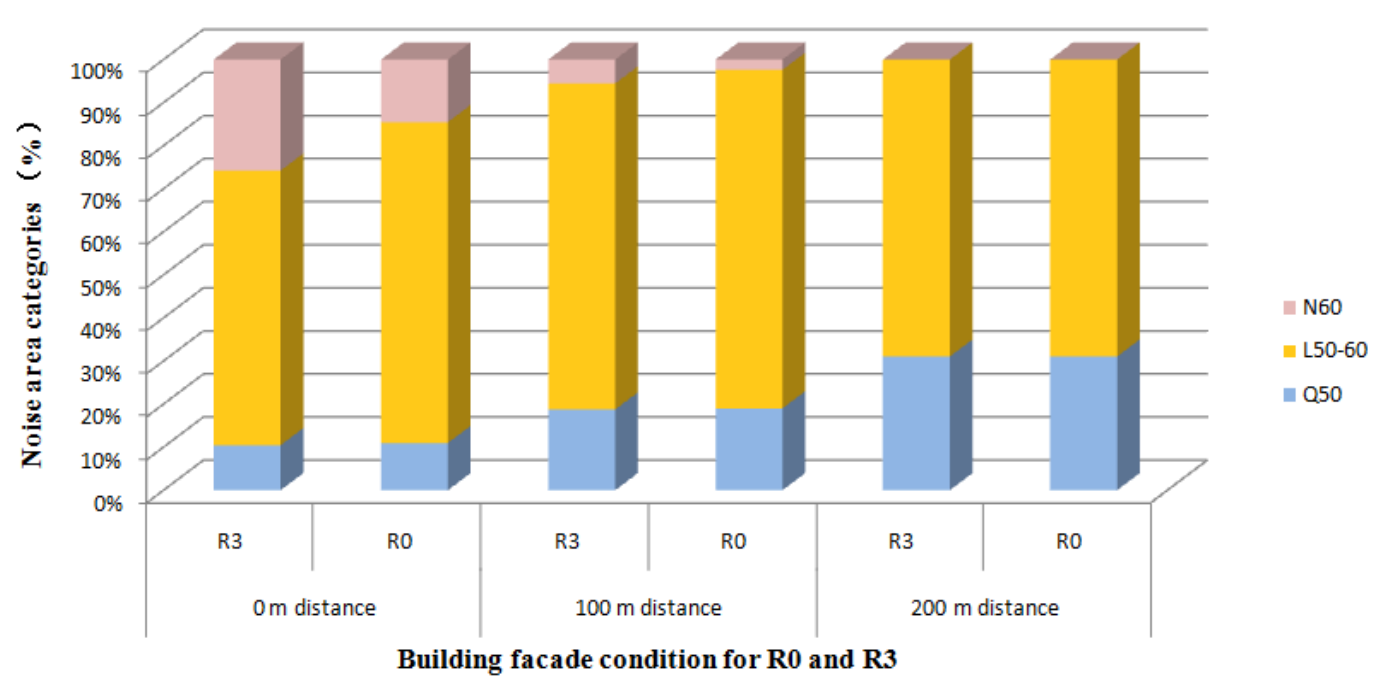

Figure 3. Effective distance of building façade condition on the traffic noise level attenuation analysis histogram.

\subsection{Influence of height of elevated road on sound environment of villages}

\subsubsection{Influence of height of elevated road}

To understand the influence of the height of elevated road on sound propagation, this study compared and investigated the influence of various heights of elevated roads on the resistance of villages to noise when the distance between the road and the village was $0 \mathrm{~m}$. The greater the height of the elevated road is, the larger the formed sound shadow area is, which seems to be more favourable for noise reduction. When the height of the elevated road was $0 \mathrm{~m}$, the first row of village buildings close to the road became effective noise barriers. When the height of elevated road was $18 \mathrm{~m}$, the first row of village buildings close to the road was affected by the sound shadow area of the elevated road and a low sound pressure level was observed there. The elevation of the sound source led to the increase in the direct sound of road traffic experienced in the village. The second row of village buildings close to the elevated road exhibited a sound barrier effect (Fig. 4a and Fig. 4b).

This study further verified the conclusion that the greater the height of the elevated road, the lesser the N60 level. When the height of the elevated road increased from $0 \mathrm{~m}$ to $30 \mathrm{~m}$, N60 decreased by $25.7 \%$. When the height of the elevated road increased from $10 \mathrm{~m}$ to $20 \mathrm{~m}$, N60 of the sample village decreased from $21.57 \%$ to $4.57 \%$, which is a $17 \%$ reduction, showing a significant noise reduction effect. The tendencies of 'noisy areas' with varying height can basically be illustrated by a logarithmic regression analysis, with $\mathrm{R}^{2}=0.868$. The reason for this difference with ISO 9613-2 might be related to the self-screening of the elevated road and the $1 \mathrm{~m}$ 
parapet. Q50 increased from a minimum value of $6.67 \%$ to a maximum value of $9.83 \%$ and experienced a change of approximately $3 \%$ when the height of the elevated road increased from $0 \mathrm{~m}$ to $10 \mathrm{~m}$. When the height of the elevated road increased to $30 \mathrm{~m}, \mathrm{Q} 50$ decreased to $7.4 \%$. It could be observed that the relationship between the evaluation indices of the sound pressure level and the height of the road was nonlinear. In this case, through a comprehensive comparison, the height of elevated road at about $20 \mathrm{~m}$ was found to be the most effective height for achieving noise reduction (Fig. 5).

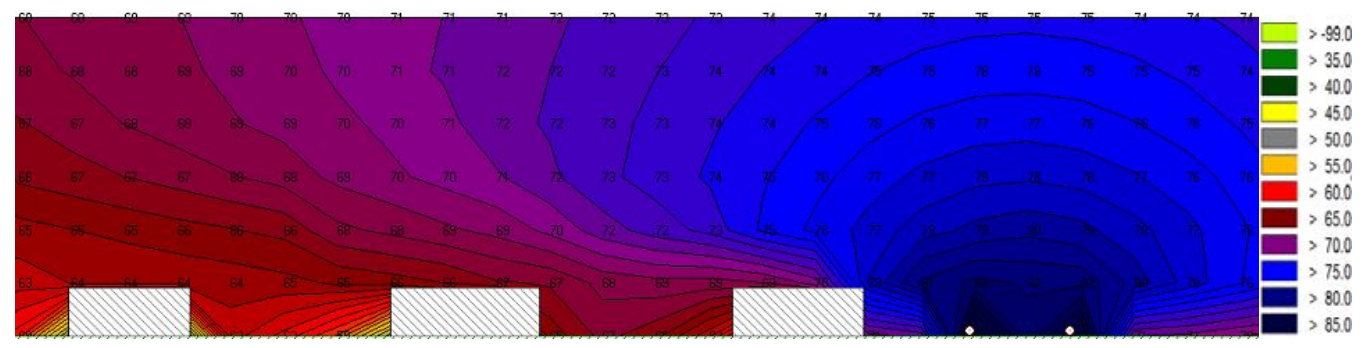

(a) $0 \mathrm{~m}$

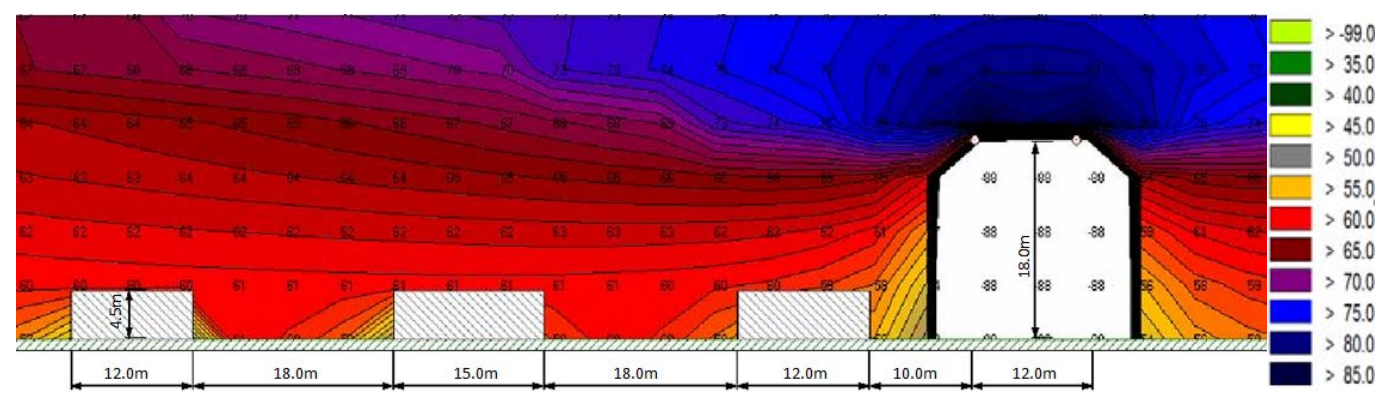

(b) $18 \mathrm{~m}$

Figure 4. Cross-section of sound maps of road and elevated road (18 $\mathrm{m}$ high).

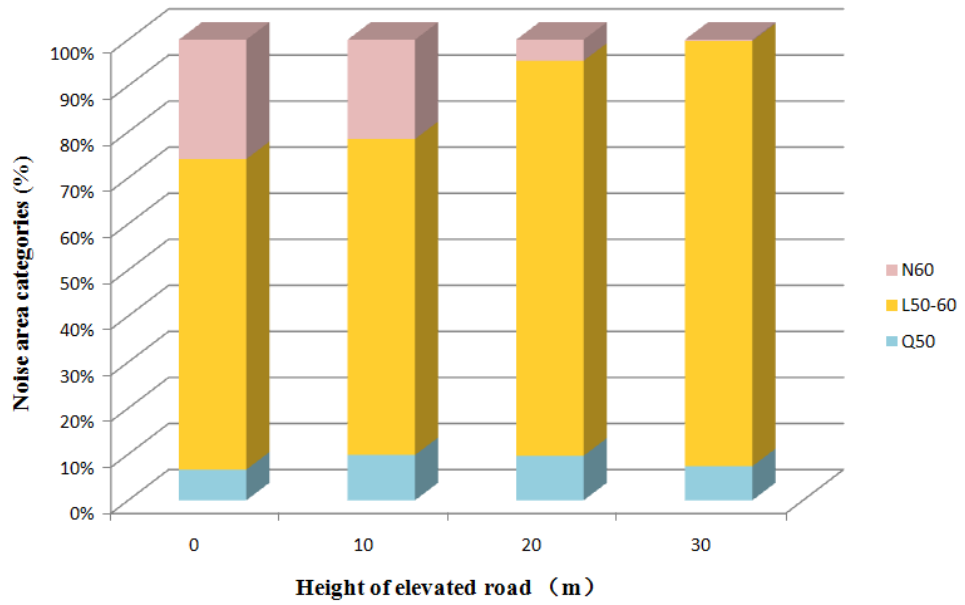

Figure 5. Variances of the noise area category indices among the 60 sites with the height of elevated road. 
The above observation might have been made because the pavement of the elevated road and the protection walls could be considered as sound barriers, which means that the acoustic path difference due to the screening effect was the difference in the value between the straight-line distance of the noise source of the elevated road to the village and the indirect distance of the noise source of the road after bypassing the sound barriers. The screening effect of the sound path difference was found to be significant when the height of the road was approximately $20 \mathrm{~m}$.

\subsubsection{Influence of sound barrier of elevated road}

The research area of the villages was a plane area. Therefore, in this study, considering the maximum, median, and minimum area, and CAR and PD, three typical villages H13 (50 hectares), K11 (32 hectares), and H20 (11 hectares) were chosen from the 60 sites for analysis (Fig. 2).

An example was considered in which the distance between the road and the village was $0 \mathrm{~m}$ and the height of the sound barrier was $3 \mathrm{~m}$. When the height of the elevated road was $10 \mathrm{~m}$ and $20 \mathrm{~m}$ respectively, the effective length of the sound barrier for the small villages was $800 \mathrm{~m}$ along both sides of the village parallel to the direction of the road, and the effective length of the large- and medium-sized villages was $2,000 \mathrm{~m}$ along both sides of villages parallel to the direction of the road. When the height of the elevated road was $30 \mathrm{~m}$, the effective lengths of the sound barrier for all the villages were $2,000 \mathrm{~m}$ along both sides of the villages parallel to the direction of the road. In addition, the most efficient length of the sound barrier was approximately $600 \mathrm{~m}$ on both sides of the villages regardless of the area of villages (Fig. 6).

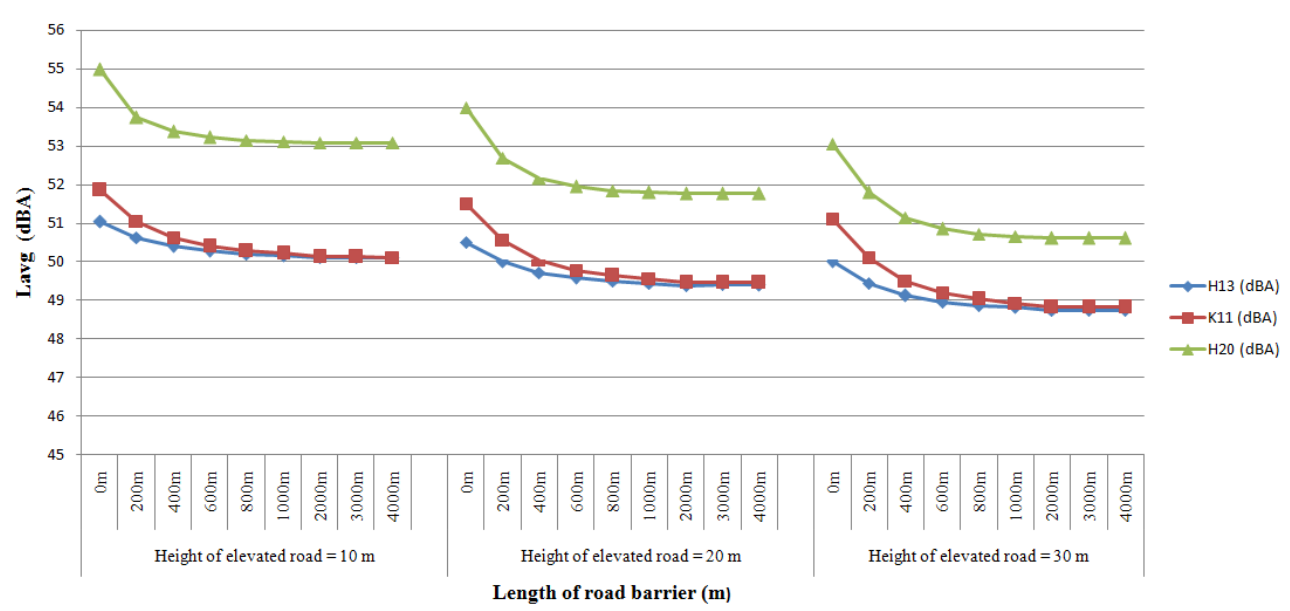

Figure 6. Variances of spatial traffic noise attenuation Lavg with changing length of road barrier ( $3 \mathrm{~m}$ high) and height of elevated road between the three sites (H13, K11, and H20) and the elevated road. 
The sound barrier of elevated roads is generally $1 \mathrm{~m}$ to $5 \mathrm{~m}$. In order to eliminate the influence of the length of the sound barrier (the length of barrier extended by 4,000 $\mathrm{m}$ along both sides of villages), this study considered an elevated road with a height of $30 \mathrm{~m}$ as an example because the variances observed with this consideration would be greater than those observed for the elevated road heights of $0 \mathrm{~m}, 10 \mathrm{~m}$, and $20 \mathrm{~m}$. Lavg was reduced by approximately $1.5 \mathrm{dBA}$ on average among three typical samples for each increase of $1 \mathrm{~m}$ in the height of the sound barrier. However, the increase in the height of the sound barrier did not show a simple linear relationship with the attenuation of Lavg. It was observed that the influence of the increase in the height of the road on the sound environment of large- and medium-sized villages was slightly greater than that on small villages. The noise experienced in large- and medium-sized villages was reduced by $2 \mathrm{dBA}$, which was more than that in small villages, on average (Fig. 7).

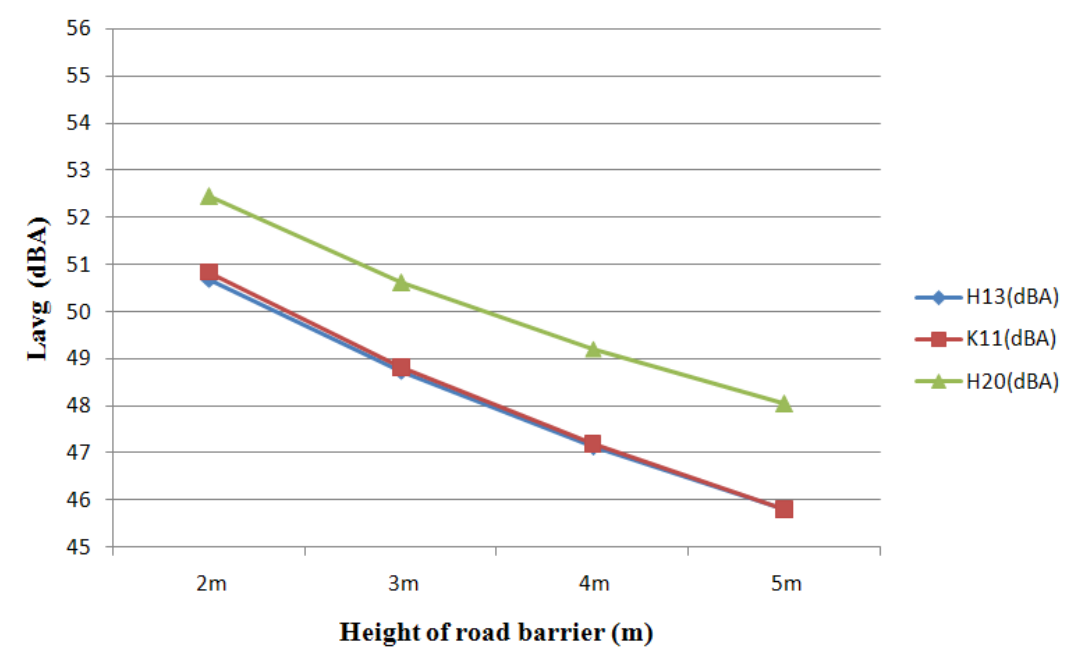

Figure 7. Variances of the spatial traffic noise attenuation Lavg with changing height of road barrier between the three sites (H13, K11, and H20) and the $30 \mathrm{~m}$ high elevated road.

\subsection{Influence of morphological parameters of villages}

\subsubsection{Relationship between sound evaluation indices and morphological parameters}

Considering that the two noise area categories (area ratio N60 of noisy areas and area ratio of quiet areas Q50) of villages in severely cold areas were potentially correlated with the six morphological parameters, SPSS 21.0 was used in this study to compute the Spearman correlation (the results of the Pearson correlation coefficients were very close to those of the Spearman correlation analysis; however, because not all the variables satisfy the normal distribution, it is not appropriate to use the Pearson correlation analysis) (Du, 2010). When the distance was $0 \mathrm{~m}$, N60 
was significantly correlated with LSI_B, PD, and RLF $(\mathrm{p}<0.01)$ as well as with CAR, RIF, and LSI_R $(\mathrm{p}<0.05)$. When the distance was more than $100 \mathrm{~m}$, N60 was 0 . In addition, Q50 was significantly correlated with LSI_B and LSI_R $(p<0.01)$ for distances of $0 \mathrm{~m}, 100 \mathrm{~m}$, and $300 \mathrm{~m}$, as well as with CAR when the distance was $0 \mathrm{~m}$ and $100 \mathrm{~m}(\mathrm{p}<0.05)$ (Table 7).

Table 7. Spearman's rho correlations between the noise area category indices Q50 in the villages and the urban morphological parameters (2-tailed). Significant correlations are marked with * $(\mathrm{p}<0.05)$ and $* *(\mathrm{p}<0.01)$.

\begin{tabular}{|c|c|c|c|c|c|c|c|}
\hline \multirow{2}{*}{$\begin{array}{c}\text { Distance } \\
(\mathrm{m})\end{array}$} & \multirow{2}{*}{$\begin{array}{l}\text { Indices } \\
\text { (\%) }\end{array}$} & \multicolumn{6}{|c|}{ Urban morphological parameters } \\
\hline & & CAR & LSI_B & PD & RLF & RIF & LSI_R \\
\hline 0 & N60 & $.300^{*}$ & $-.416^{* *}$ & $.346^{* *}$ & $.358^{* *}$ & $.257^{*}$ & $-.297^{*}$ \\
\hline 0 & Q50 & $-.287^{*}$ & $.684^{* *}$ & -.228 & -.106 & -.018 & $.692^{* *}$ \\
\hline 100 & Q50 & $-.256^{*}$ & $.640^{* *}$ & -.213 & -.054 & .045 & $.662^{* *}$ \\
\hline 300 & Q50 & -.099 & $.403^{* *}$ & -.097 & -.107 & -.046 & $.402^{* *}$ \\
\hline
\end{tabular}

Furthermore, a regression analysis was conducted on the significantly correlated parameters $(\mathrm{p}<0.01)$. Because the regression analysis results $\left(\mathrm{R}^{2}\right)$ of $\mathrm{N} 60$ (N60-LSI_B inverse regression analysis $\mathrm{R}^{2}=0.269$; N60-PD cubic regression analysis $R^{2}=0.164$; N60-RLF cubic regression analysis $R^{2}=0.096$ ) were less than 0.3 and the regression effect was poor, a stepwise multiple regression analysis was performed after considering the other parameters, HWR_V $(0.40)$, LSI_B $(-0.35)$, and RLF (0.26), that caused a change in N60. The results showed that $\mathrm{R}^{2}=0.436<$ 0.5 , and the regression effect was still poor.

In this study, a regression analysis was conducted on Q50-LSI_B and Q50-LSI_R, and the representative distances of $0 \mathrm{~m}$ and $100 \mathrm{~m}$ were considered as examples. When the distance was $0 \mathrm{~m}$, two groups of parameters could be related linearly (Fig. 8).

Q50 could be increased by approximately 68\% with the increase in LSI_B from 5.824 to 24.103, as can be seen in Fig. 8a. This was probably because increasing the complexity of the buildings in villages could improve the sound barrier effect of those buildings. On comparing the village samples with various LSI_B values, it was found that large villages with multiform buildings or a mixed layout showed a strong anti-noise performance. As $\mathrm{R}^{2}<0.5$, a multiple stepwise regression analysis was 
conducted. The results showed that LSI_B and HWR were significantly correlated with Q50. When $\mathrm{R}^{2}=0.645$, Q50 was positively correlated with LSI_B (0.587) and negatively correlated with HWR $(-0.418)$. As a result, a reduction in the distance between the village buildings along the vertical direction of the elevated road would be conducive to enhancing the anti-noise performance of the village. The reason for this might be the increase in the sound barrier effect of the buildings.

Q50 could be increased by about 65\% with an increase in LSI_R from 6.688 to 25.420 , as can be seen in Fig. $8 \mathrm{~b}$. This was probably because increasing the complexity of the road form contributed to reducing the transmissivity of the sound propagation from the road and thus achieved the effect of noise reduction. As $\mathrm{R}^{2}<$ 0.5 , a multiple stepwise regression analysis was conducted. The results showed that LSI_R and RLF were significantly correlated with Q50 and $\mathrm{R}^{2}=0.650$. Q50 was positively correlated with LSI_R (0.849) and negatively correlated with RLF $(-0.427)$. Therefore, reducing the length of the road and cutting down the number of main village roads running through the villages or complicating the road form would be conductive to enhancing the anti-noise performance of villages.

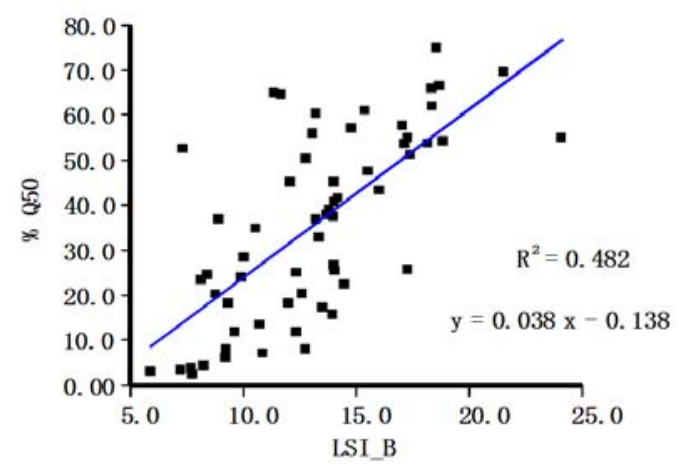

(a) LSI_B

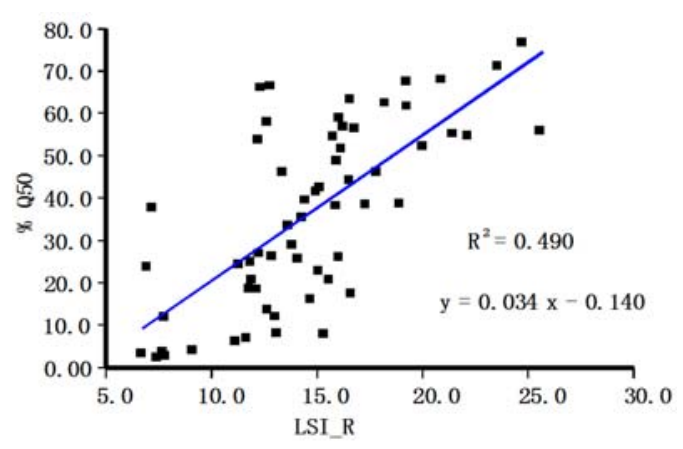

(b) LSI_R

Figure 8. Respective relationships between quiet areas Q50 in the villages and the landscape shape index of buildings (LSI_B) and the landscape shape index of roads (LSI_R) for a distance of $0 \mathrm{~m}$.

When the distance was $100 \mathrm{~m}$, Figs. 9a and $9 \mathrm{~b}$ show the results of a quadratic regression analysis: LSI_B and LSI_R caused an increase in the 'quiet areas' of villages by $49.1 \%$ and $51 \%$, respectively. Because the values of $\mathrm{R}^{2}$ were both less than 0.5 , a multiple stepwise regression analysis was conducted. The results showed 
that LSI_B, CAR, and BPAF were significantly correlated with Q50, and $\mathrm{R}^{2}=0.632$. Q50 was positively correlated with LSI_B (0.733) and BPAF (0.278), and negatively correlated with CAR $(-0.574)$. Therefore, reducing the area of roofs and height of buildings would contribute to reduction in the sound reflection between buildings and achieve the effect of noise reduction. Reducing the ratio of the bare ground area $A_{G}$ would contribute to improving the sound barrier and sound absorption effect of buildings and enhance the anti-noise performance of the villages. In addition, RLF and RIF were the other two variables associated with Q50 in addition to LSI_R with $\mathrm{R}^{2}=0.605$. Q50 was positively correlated with LSI_R (0.791) and RIF (0.321) and negatively correlated with RLF ( -0.606$)$. Therefore, reducing the length of roads or using complex and diversified road connections would be conducive to enhancing the anti-noise performance of villages.

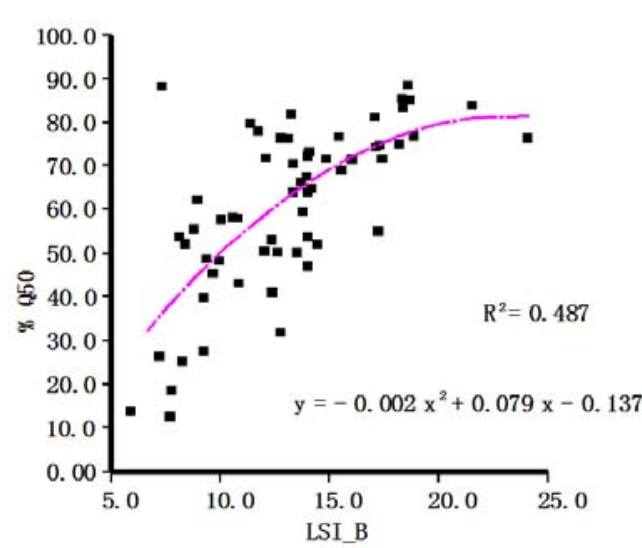

(a) LSI_B

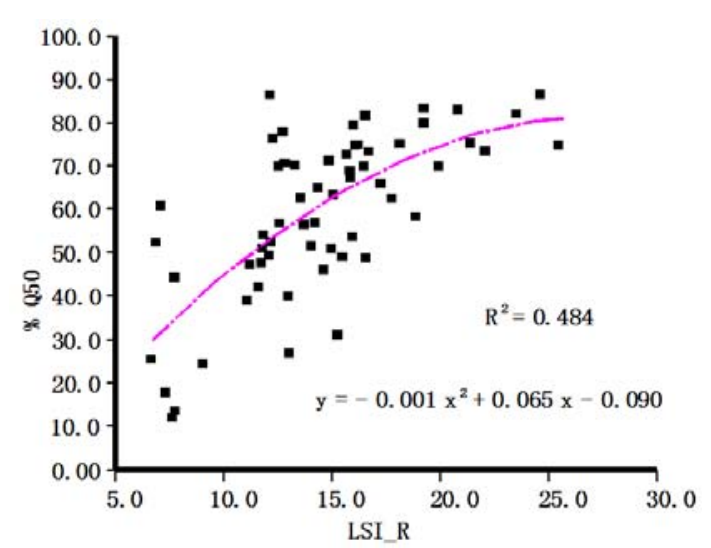

(b) LSI_R

Figure 9. Respective relationships between quiet areas Q50 in the villages and LSI_B and LSI_R for a distance of $100 \mathrm{~m}$.

\subsubsection{Relationship between the sound index of traffic noise and morphological parameters}

This study simulates the entire process of spatial sound attenuation in the context of various urban morphologies in villages. Accordingly, sets of indices that represent the entire attenuation process are investigated in order to identify the most sensitive indices with the highest variances caused by urban morphology.

For the various distances, the greater the difference between the maximum and minimum values $\left(\mathrm{Ln}_{\max }-\mathrm{Ln} \mathrm{n}_{\min }\right)$ of the statistical sound levels from $\mathrm{L} 10$ to $\mathrm{L} 90$, the greater the sensitivity to the attenuation of sound propagation. A diagram showing the sensitivity of the acoustic parameters was thus extracted. When the distance was $0 \mathrm{~m}$, the maximum difference in noise occurs at L80, and a difference of more than 
$10 \mathrm{dBA}$ was observed with the mean of the difference between the maximum and minimum values. When the distance was $100 \mathrm{~m}$ and $300 \mathrm{~m}$, the value of $\mathrm{Ln}_{\max }-\mathrm{Ln}_{\min }$ of $\mathrm{L} 10$ was the largest, varying by more than $8 \mathrm{dBA}$ and $6 \mathrm{dBA}$, respectively, with the mean of the difference between the maximum and minimum values (Fig. 10). Therefore, the selection of sound indices of sensitivity is as follows: L80 for $0 \mathrm{~m}$ and L10 for $100 \mathrm{~m}$ to $300 \mathrm{~m}$.

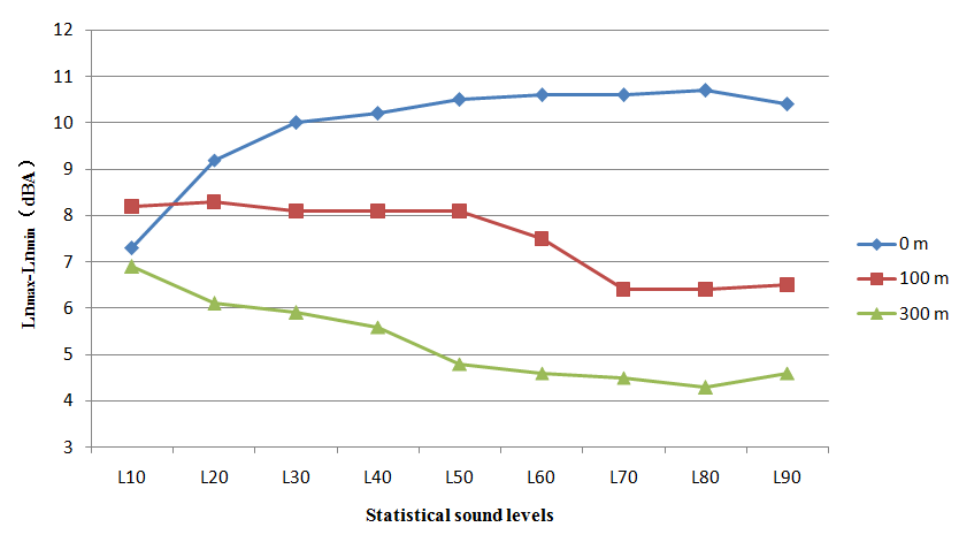

Figure 10. Statistical sound level indices of the 60 sites with the mean difference between the maximum and minimum values shown for each index. The various coloured lines represent distances of $0 \mathrm{~m}, 100 \mathrm{~m}$, and $300 \mathrm{~m}$ between the site and the elevated road.

This study computed the Spearman correlation between the indices of the sound pressure levels and morphological parameters. For the various distances, LSI_B and LSI_R were significantly correlated with the indices of the statistical sound levels $(\mathrm{p}<0.01)$. RLF and RIF were not correlated with any other acoustic indices (Table 8). Similarly, the distances of $0 \mathrm{~m}$ and $100 \mathrm{~m}$ were considered as examples. This study further conducted a regression analysis on the related parameters. When the distance was $0 \mathrm{~m}$, L80-LSI_B and L80-LSI_R could be predicted using an inverse function and a quadratic relationship, respectively (Fig. 10).

Table 8. Correlations between spatial traffic noise levels in the villages and urban morphological parameters (2-tailed). Significant correlations are marked with $*(p<0.05)$ and $* *(p<0.01)$.

\begin{tabular}{|c|c|c|c|c|c|c|c|}
\hline \multirow{2}{*}{$\begin{array}{c}\text { Distance } \\
(\mathbf{m})\end{array}$} & \multirow{2}{*}{$\begin{array}{c}\text { Indices } \\
\text { (dBA) }\end{array}$} & \multicolumn{6}{|c|}{ Urban morphological parameters } \\
\hline & & CAR & LSI_B & $\mathrm{PD}$ & RLF & RIF & LSI_R \\
\hline 0 & L80 & $.289^{*}$ & $-.686^{* *}$ & .249 & .117 & .012 & $-.690^{* *}$ \\
\hline 100 & L10 & $.259^{*}$ & $-.470^{* *}$ & $.284^{*}$ & .133 & .036 & $-.424^{* *}$ \\
\hline 300 & L10 & 021 & $-.481^{* *}$ & .029 & .056 & .015 & $-.490^{* *}$ \\
\hline
\end{tabular}


When LSI_B $\leq 12$, L80 sharply decreased by $6.2 \mathrm{dBA}$ with the increase in LSI_B, and when LSI_B $>12$, L80 gradually decreased by 3 dBA (Fig. 11a). This was probably because increasing the complexity of building form in the villages could lead to more sound reflection between buildings and thus reduce the sound barrier effect of the buildings. L80 could decrease by approximately $8.4 \mathrm{dBA}$ with the increase in LSI_R (Fig. 11b). This was probably because increasing the complexity of the road form in rural residential areas was conducive to reducing the sound propagation through the streets along the roads and achieving the effect of noise reduction.

When the distance was $100 \mathrm{~m}$, there was no specific change rule between the variables of the scatter diagram of L10-LSI_B and L10-LSI_R. In various instances in the curve regression, $\mathrm{R}^{2}$ was less than 0.2 . In addition, $\mathrm{R}^{2}$ was less than 0.4 in the multiple regression equations. Therefore, it could be neglected.

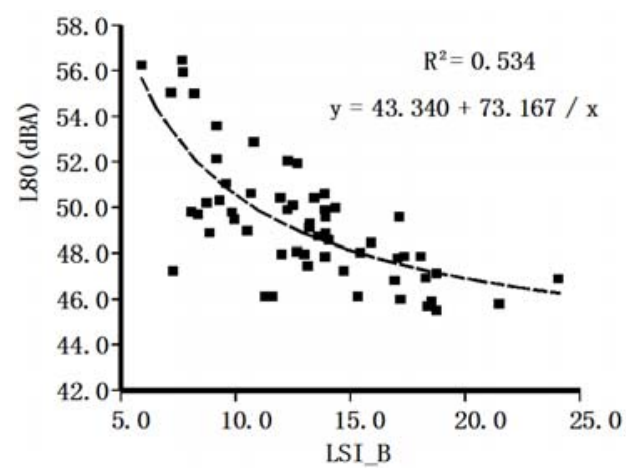

(a) LSI_B

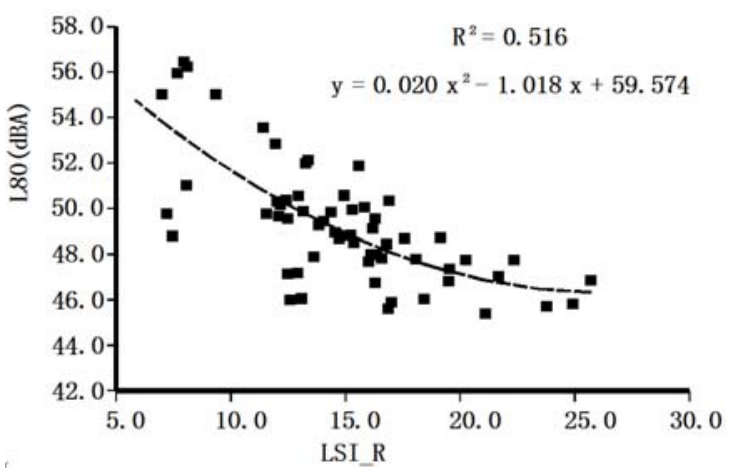

(b) LSI_R

Figure 11. Respective relationships between the spatial noise level indices L80 in the villages and LSI_B and LSI_R for a distance of $0 \mathrm{~m}$.

\section{Conclusions}

The problem of traffic noise from elevated roads is extremely serious in rural villages. In this study, the methods of improving the anti-noise properties of villages through a systematic design were investigated, and the following conclusions were drawn:

1. Increasing the distance between villages and elevated roads could effectively reduce the influence of traffic noise on villages; however, there would be significant differences in the noise reduction effect for villages of different forms. Thus, it was 
necessary to consider the design of building facades and the noise reduction effect caused by the village forms. For samples of a typical village form, the proportion of 'quiet areas' could increase by approximately $10 \%$ for each increase of $100 \mathrm{~m}$ in the distance between the elevated road and the village. When the distance was $300 \mathrm{~m}$, the proportion of noisy areas was 0 , which would satisfy the standard of Class 2 sound environment functional areas according to the 'Environmental Quality Standard for Noise' (GB3096-2008). When the distance was $600 \mathrm{~m}$, the Class 1 living standard could be satisfied. The Class 0 standard could be satisfied when the distance between the elevated road and the village was more than $1,000 \mathrm{~m}$. The effective distance in the design for the noise reduction of building facades was approximately $100 \mathrm{~m}$. When the distance was more than $100 \mathrm{~m}$, there would be no requirement for considering noise reduction measure such as changing the materials of the building facades or designing vertical greenery systems.

2. The sound shadow area formed by a higher elevation road would be more conducive to noise reduction. When the height of the elevated road increased from $0 \mathrm{~m}$ to $30 \mathrm{~m}$, N60 decreased by $25.7 \%$. The influence of the height of elevated road on the occurrence of 'noisy areas' was more significant than that of Q50. In comparison, the sound barrier effect of the sound path difference caused by the elevated road with a height at about $20 \mathrm{~m}$ was the most significant. When the height of the elevated road was $10 \mathrm{~m}$ to $30 \mathrm{~m}$, the sound barrier was $3 \mathrm{~m}$ high. Regardless of the village area, the most economical and efficient length of the sound barrier was approximately $600 \mathrm{~m}$ along both sides of the village parallel to the road. In addition, the influence of the length of the sound barrier was neglected. For each increase of $1 \mathrm{~m}$ in the height of the sound barrier, Lavg of the three typical samples reduced by approximately $1.5 \mathrm{dBA}$, on average. The sound environments of large- and medium-sized villages were affected by the height of the sound barrier to some extent, and a noise reduction of approximately $0.2 \mathrm{dBA}$ more than Lavg in small villages was observed.

3. Decreasing the spatial traffic noise levels of an elevated road and enlarging the quiet areas in villages by controlling the urban morphological parameters of villages are efficient measures of noise reduction. As shown in the single element and multiple regression analyses, there are a series of significant relationships between the spatial traffic noise levels and the urban morphological parameters, with $\mathrm{R}^{2}>$ 0.5. In addition, the morphological parameters affecting the noise attenuation were different for the various distances. When the distance was $0 \mathrm{~m}$, the 'quiet areas' had a positive relationship with the indices of the buildings, LSI_B and LSI_R, and a 
negative relationship with HWR and RLF. When the distance was $100 \mathrm{~m}$, the 'quiet areas' are positively associated with LSI_B, BPAF, LSI_R, and RIF and negatively associated with CAR and RLF. In terms of the spatial noise level indices, L80 has a negative relationship with LSI_B and LSI_R. In addition, the 'noisy areas' did not show an obvious relationship with the morphological parameters of the villages when the distance was $0 \mathrm{~m}$, and L10 did not show an obvious relationship with LSI_B or LSI_R when the distance was $100 \mathrm{~m}$.

This study examines the methods of reducing elevated-road traffic-noise levels in rural residential areas. Based on previous research results, it systematically revealed whether and how relative locations and morphological parameters influence the spatial noise level attenuation of elevated roads. In addition, the effects of noise barriers and building facades in villages on noise attenuation were also examined. Overall, by filling the gaps in previous studies, this study is expected to provide guidance and data for village and elevated road designers and local authorities, particularly relating to the village planning system in cold areas in China. However, the results cannot be applied to other climates and geographical environments, such as rural villages in severely hot areas (for a larger building density, a larger number of reflections will be set up) and mountainous regions, whose terrain has a great influence on the noise prediction results. The influence of topography on the acoustic environment should be considered in actual elevated composite road projects. Mountainous regions, being huge acoustic barriers, require consideration of more influencing factors owing to the complexity of the acoustic environment (form, layout, scale, and the sound absorption coefficient of the mountain). Research methods are available for reference on similar issues in other climates and geographical environment. 


\section{References}

[1] Avsar, Y., and M. T. Gonullu. 2005. "Determination of Safe Distance Between Roadway and School Buildings to Get Acceptable School Outdoor Noise Level by Using Noise Barriers.” Building and Environment 40 (9): 1255-1260.

[2] Burian, S. J., W. S. Han, and M. J. Brown. 2005. Morphological Analyses Using 3D Building Databases: Oklahoma City, Oklahoma. LA-UR-05-1821. Los Alamos, NM: Los Alamos National Laboratory.

[3] Chen, X. Y., and H. B. Xiong. 2013. "Prediction and Control Techniques Research on Environmental Effect of Noise from Elevated Roads.” MSc Thesis, Harbin Institute of Technology.

[4] Chen, Y. L., Q. Sun, W. Wei, K. B. Liu, and C. M. Liu. 2007. "Investigation on Traffic Noise Pollution Caused by Overhead Road." Environmental Health : A Global Access Science Source 24 (10): 795-797.

[5] DataKustik GmbH. 2006. Cadna/A for Windows: User Manual. Munich: Kustik.

[6] Du, Z. M. 2010. Sample Survey and the Application of SPSS Software. Beijing: Electronics Industry Publishing.

[7] Fritschi L., A. L. Brown, R. Kim, D. H. Schwela, and S. Kephalopoulos, eds.2011. Burden of Disease from Environmental Noise: Quantification of Healthy Life Years Lost in Europe. Geneva: World Health Organisation, Regional Office for Europe. http://www.euro.who.int/_data/assets/pdf_file/0008/136466/e94888.pdf.

[8] GB 3096-2008, 2008. Environmental Quality Standard for Noise. Beijing: State Environmental Protection Administration of China.

[9] Hao, Y., and J. Kang. 2014. "Influence of Mesoscale Urban Morphology on the Spatial Noise Attenuation of Flyover Aircrafts." Applied Acoustics 84 (84): 73-82.

[10]Hao, Y., J. Kang, D. Krijnders, and H. Wörtche, 2015. "On the Relationship Between Traffic Noise Resistance and Urban Morphology in Low-Density Residential Areas." Acustica/acta Acustica-European Journal of Acoustics 101 (3): 510-519 (10).

[11]He, P., and H. R. Zhang. 2009. "Study on Factor Analysis and Selection of Common Landscape Metrics." Forest Research 22: 470-474.

[12]He, Y., and J. Kang. 2014. "Differences Between Rural and Urban Sound Environment in Northeast of China." MSc Thesis, Harbin Institute of Technology, $10-19$.

[13]Heilongjiang Provincial Bureau of Statistics. 2014. Heilongjiang Statistical Yearbook. Beijing: China Statistics Press.

[14]ISO 9613-2, 1996, Acoustics - Attenuation of Sound During Propagation Outdoors - Part 2: General Method of Calculation. Geneva: International Standards Organization.

[15]JTG D20-2006. 2006. Design Specification for Highway Alignment. Beijing: China's Ministry of Transport.

[16]Kang, J. 2007. Urban Sound Environment. London: Taylor \& Francis.

[17]Kim, M. J., and H. G. Kim. 2007. "Field Measurements of Façade Sound Insulation in Residential Buildings with Balcony Windows." Building and 
Environment 42 (2): 1026-1035.

[18]Ko, J. H., S. I. Chang, M. Kim, J. B. Holt, and J. C. Seong. 2011. "Transportation Noise and Exposed Population of an Urban Area in the Republic of Korea." Environment International 37 (2): 328-334.

[19]Lam, K. C., W. Ma, P. K. Chan, W. C. Hui, K. L. Chung, Y. T. Chung, C. Y. Wong, and H. Lin. 2013. "Relationship Between Road Traffic Noisescape and Urban Form in Hong Kong." Environmental Monitoring and Assessment 185 (12): 9683-9695.

[20]Li H., Z. D. Li, and M. Li. 2012. "Application of Cadna/A Software in Prediction and Assessment of Expressway Noise." Environmental Science and Management 37 (1): 168-172.

[21]Li, X., and S. W. Yang. 2013. "Key Technology for Expressway Land Intensive Economical Use and Comprehensive Evaluation on Its Effect." $\mathrm{PhD}$ Thesis, Chang' an University.

[22]Li, G. X., J. Y., Zhu, and Y. M. Sun. 2007. "Feasibility Study on Applying Rubber Road Pavement on Urban Viaducts to Reduce Vibration or Noise." Technology of Highway and Transport 5: 127-129.

[23]Liu, L. Q. 2008. “The Discussion of a New Design Idea: Bridges Instead of Roads and Bridges Instead of Tunnels." Highway Engineering 33 (2): 114-117.

[24]Liu, J., J. Kang, H. Behm, and T. Luo. 2014. "Effects of Landscape on Soundscape Perception: Soundwalks in City Parks." Landscape and Urban Planning 123 (1): 30-40.

[25] Ma, X., and S. Li. 2009. "Optimization Design of L-Shaped Road Noise Barrier and Cost-Effectiveness Analysis." In Proceedings for the 2009 IEEE Intelligent Vehicles Symposium, 998-993. New York: IEEE. doi:10.1109/IVS.2009.5164415

[26]Mei, L., and J. Kang. 2014. "Research on Courtyard Acoustic Environment of Rural Housing in Severe Cold Area of Northeast China." MSc Thesis, Harbin Institute of Technology.

[27] Mei, L., J. Kang, and M. Huang. 2016. "Acoustic Comfort Evaluation and its Influencing Factors in Courtyards of Cold Rural Regions." Building Science 32 (2): 43-47.

[28]Meng, X. Q., and J. Kang. 2014. "The Interact Between the Main Road Traffic Noise and the Village Planning of Northeast." MSc Thesis, Harbin Institute of Technology.

[29]Murthy, V. K., A. K. Majumder, S. N. Khanal, and D. P. Subedi. 2010. "Assessment of Traffic Noise Pollution in Banepa: A Semi Urban Town of Nepal.” Kathmandu University Journal of Science Engineering and Technology 3 (2): $12-20$.

[30]Oke, T. R. 1988. "Street Design and Urban Canopy Layer Climate." Energy and Buildings 11 (1-3):103-113.

[31]Rey Gozalo, G., J. M. BarrigónMorillas, and V. Gómez Escobar. 2012. “Analysis of Noise Exposure in Two Small Towns.” Acta Acustica United with Acustica 98 (6): 884-893.

[32]Rey Gozalo, G., J. M. BarrigónMorillas, V. Gómez Escobar, R. Vílchez-Gómez, J. 
A. Méndez Sierra, and F. J. Carmona del Río, et al., 2013. "Study of the Categorisation Method Using Long-Term Measurements." Archives of Acoustics 38 (3): 397-405.

[33] Salomons, E. M., and M. B. Pont. 2012. "Urban Traffic Noise and the Relation to Urban Density, Form, and Traffic Elasticity." Landscape and Urban Planning 108 (1): $2-16$.

[34] Shao, T., H. Jin, and L. H. Zhao. 2016. "The Existing Situation and Improving Strategies for Rural Housings in the Northeast Severe Cold Regions." China Sciencepaper 11 (1): 12-16.

[35] Sobotova, L., J. Jurkovicova, Z. Stefanikova, L. Sevcikova, and L. Aghova. 2010. "Community Response to Environmental Noise and the Impact on Cardiovascular Risk Score." The Science of the Total Environment 408 (6): 1264-1270.

[36] Stephen, M. 2004. Street and Patterns. London: Taylor \& Francis.

[37] Sun, H. T., P. J. Liu, and H. W. Wang. 2010. "The Noise Prediction of Urban Elevated Road Based on Cadna /A." South China Normal University (Natural Science Edition) 1: 58-61.

[38] Voogt, J. A., and T. R. Oke. 1997. "Complete Urban Surface Temperatures." Applied Meteorology 36 (9): 1117-1132.

[39] Wang, X. J. 2014. "Current Situation and Development Trend of Rural Building." Nong Min Zhi Fu Zhi You 11: 154-154.

[40]Wang, Y. P., and L. Gai. 2012. "Study on the Distribution of Sound Field in Vertical Plane of Traffic Noise for City Elevated Complex Road." Noise and Vibration Control 5: 136-140.

[41] Wang, B., and J. Kang. 2011. "Effects of Urban Morphology on the Traffic Noise Distribution Through Noise Mapping: A Comparative Study Between UK and China." Applied Acoustics 72 (8): 556-568.

[42] Wong, N. H., A. Y. K. Tan, P. Y. Tan, K. Chiang, and N. C. Wong. 2010. "Acoustics Evaluation of Vertical Greenery Systems for Building Walls." Building and Environment 45 (2): 411-420.

[43]Wu, C. S. 1998. "Properly Replace Railway by Bridge and Economize on Good Farmland: A Great Contribution for People.” Railway Engineering Society 15 (1): $35-38$.

[44]Xi, O., Y. M. Zeng, Y. Shen, X. W. Wei, Y. Q. Wang, and M. M. Yuan. 2015. "Discussion on Domestic Rural Noise Pollution Status and its Control Measures." Noise and Vibration Control 35 (2): 131-136.

[45] Yang, Y. M. 2016. "Effects of Elevated Road on Noise Environment of Neighbouring Street Residential Building." Environmental Science and Management 41 (9): 60-64.

[46] Yang, H. S., J. Kang, and M. S. Choi. 2012. "Acoustic Effects of Green Roof Systems on a Low-Profiled Structure at Street Level." Building and Environment 50 (4): 44-55.

[47] Yari, A., B. Dezhdar, A. Koohpaei, A. Ebrahimi, A. Mashkoori, M. J. Mohammadi, and S. A. Jang. 2016. "Evaluation of Traffic Noise Pollution and Control Solutions Offering: A Case Study in Qom, Iran.” Kerman University of 
Medical Sciences, 23 (4): 600-607.

[48] Ye, J., G. H. Xia, and B. Hu. 2016. "Space Distribution and Control Measures of Elevated Road Traffic Noise of Wenling City." Environmental Science and Management, 41 (6): 133-136.

[49] Yu, W. Z. 2008. "Noise Reduction Effect of Sound Barrier of Elevated Road." Chinese Journal of Environmental Engineering 2 (6): 844-847.

[50] Yu, X. F., and Y. Gao. 2013. "On Sensitivity Analysis of Various Acoustic Barriers on Noises at Viaducts." Shanxi Architecture 39 (20): 194-196.

[51] Yu, W. L., and J. Kang. 2016. "Analysis of the Integrated Effects of Village Form on Traffic Noise Resistance in Severe Cold Region." Urbanism and Architecture 28: 109-113.

[52]Yu, W. L., and J. Kang. 2017. "Relationship Between Traffic Noise Resistance and Village Form in China." Landscape and Urban Planning 163: 44-55.

[53]Zhang, L. J. 2014. "Study on Analysis and Control Technology of Noise Situation Surrounding Viaduct at Changzhou." MSc Thesis, Harbin Institute of Technology.

[54]Zhang, L., and Y. Rao. 2012. "Research on Simulation of Acoustics Environment and Noise Cancelling Design Strategy of the Residential District Along the Road in Hefei." MSc Thesis, Hefei University of Technology.

[55]Zhang, X. 2004. "The Characteristics of Elevated Road Traffic Noise and Noise Control." Paper presented at a conference on Green Buildings and Buildings, Southeast University, Nanjing, China, October 15-17.

[56]Zhang, T. Y., and Q. Yin. 2014. "The Research of Optimization Strategy of the Wind Environment of the Residential Buildings and the Courtyard in the Cold Region of the Northeast of China." MSc Thesis, Harbin Institute of Technology. 